\title{
Shifts in Reproductive Patterns in China
}

\author{
Tih-Fen Ting \\ University of Michigan
}

\begin{abstract}
The People's Republic of China, during the second half of the twentieth century, has been repeatedly affected by social and political upheavals associated with government policies. These have produced strong but unexpected impacts on Chinese demographic patterns. Many of these policies are of the sorts that alter reproductive costs and benefits. This study examines patterns in Hebei, Shaanxi, and Shanghai, three provinces with differing ecological, geographic, and economic characteristics. Government policies affected the three populations differentially; this was evident at both aggregate and individual levels. The Great Leap Forward and subsequent famine created higher birth deficits and mortality among the largely rural populations of Hebei and Shaanxi than the more urban Shanghai. In contrast, the Cultural Revolution and family planning resulted in lower fertility levels for women in Shanghai. The population history of China during the second half of last century thus reflects strong state interventions in the lives of its citizens. Government policies, along with regional variations in geographic, social, and economic conditions, strongly influence individual access to resources in China. Variations in timing and intensity of women's reproductive patterns reflect differential access to resources and subsequent trade-offs.
\end{abstract}

KEY WORDS: China; population; fertility; mortality; government policies.

\section{INTRODUCTION}

Populations grow and affect environments; environments in turn influence the population (demographic) patterns. Interactions between population and environment are the aggregate outcomes of individual behaviors. Better understanding of individual lifetimes and behavior should lead to better understanding of population-environment dynamics.

Please address correspondence to Tih-Fen Ting, Department of Environmental Studies, University of Illinois at Springfield, Springfield, IL 62703; e-mail: tting1@uis.edu. 
Organisms, including humans, experience a series of trade-offs among life history traits, such as age and size at maturity, allocation between somatic and reproductive effort, age schedules of birth and death, and number and size of offspring. Thus, life histories represent the outcomes of competing costs and benefits associated with different activities at any point in life (Daan \& Tinbergen, 1997; Lessells, 1991; Low, 1998; Roff, 1992; Stearns, 1992). Moreover, life histories do not operate in a vacuum, but evolve in response to environmental pressures, phylogenetic constraints, and historical particulars (see Low, 2000; Roff, 2002). Humans live in multifaceted environments that encompass ecological, social, political, and cultural settings. As a result of this complexity, human life histories can be more diverse than many other species (Low, 2000).

Life history characteristics related to reproduction are centrally important. Fertility variation has long been a focus of interest among biologists, demographers, and anthropologists (e.g., Bongaarts \& Potter, 1983; Clarke \& Low, 2001; Hill \& Hurtado, 1996; Low \& Clarke, 1993; Low, Clarke, \& Lockridge, 1992). Variations in resource availability, reflecting different social and ecological conditions, tend to give rise to variations in reproductive patterns in different environments (e.g., Hill \& Hurtado, 1996; Kaplan, 1994; Low \& Clarke, 1993).

Chinese life history data provide a unique opportunity to expand this theoretical exploration. China in the second half of the twentieth century has experienced dramatic (even shocking) social, cultural, and political transformation as a result of various government policies (Meisner, 1999; Schoppa, 2002). Many of these policy shifts are of the sort that alter reproductive costs and benefits. Examples of these transformative experiences include the extremely rapid agricultural collectivization and urban industrialization of the 1950s and early 1960s (with attendant social dislocation, famine, etc.); and the violent class warfare encouraged during the Cultural Revolution (1966-1976). Many government policies of these periods were unprecedented in human history (Meisner, 1999; Schoppa, 2002); some of them created novel environments - and subsequent reproductive responses - for the Chinese people.

In light of the vast ecological variation within China, as well as temporal variation due to various historical events, we would expect Chinese women born in different eras and from different parts of the country to respond differently in their fertility patterns. Differences in their timing and intensity of reproduction should reflect variations in their backgrounds and experiences.

Here, I focus on women from two rural provinces (Hebei and Shaanxi) and one urban municipality (Shanghai) in China. To illuminate how 
government policies affect populations, I first examine changes in birth and death rates in these three areas during the first 50 years (1949-1999) of the People's Republic of China. I then compare age-specific martial fertilities for women of a representative sample from each region. I show that at the aggregate level, fluctuations in birth and death rates responded closely to shifts in government policies. At the individual level, these policies produced shifts in fertility patterns for women of different age cohorts.

\section{MAO'S CHINA AND BEYOND}

The People's Republic of China (PRC) was formally established under the leadership of the Chinese Communist Party (CCP) on October 1, 1949. At that time, the PRC had a territory slightly larger than that of the U. S., and a population of roughly 542 million people. China's territory has not grown in the intervening 54 years, but its population has more than doubled, standing now at approximately 1.3 billion.

From 1949 until his death in 1976, Mao Zedong dominated the CCP. Mao was at the helm when the CCP implemented land reform, agricultural collectivization, nationalization of industry, nation-wide ideological indoctrination, and numerous other changes. Following Mao's death and a difficult period of transition, Deng Xiaoping emerged in 1978 as the preeminent leader of CCP (until his death in early 1997). Under Deng's leadership, the CCP implemented a series of modernization efforts (known as the Four Modernization), the one-child population control policy, and a new system of agricultural and industrial production incentives.

Consequently, between 1950 and 1985, Chinese people experienced a series of unprecedented social, economic, and political upheavals due to government reforms and movements; indeed, the period is often describe as a vast experiment in revolutionary social engineering. Based on these fundamental social and political events, the first 35 some years of the PRC can be divided into the following periods.

\section{The Transition to Socialism (TTS): 1949-1957}

The political construction led by the governing CCP during this period emphasized economic development and social equality. Land reform and the newly introduced marriage law were meant to improve the social status of women and peasants, freeing both from a "long-standing exploitation" by the feudal patriarchal establishment (but see Johnson, 1983). Income differentials were compressed between white-collar and blue-collar jobs, and 
between mental and manual labor, as a result of the ideological struggle against so-called capitalist elements (Lin \& Xie, 1988; Parish, 1984). The period of 1953-1957 marked China's First Five-Year Plan, characterized by collectivization of agriculture, industrialization, and political centralization. Preliminary collectivization of agriculture was $90 \%$ completed by the end of 1956. In addition, the government nationalized banking, many industries, and trade. Private enterprise was virtually abolished (Worden, Savada, \& Dolan, 1987).

Improvements in health and economic conditions led to an increase in life expectancy at birth from 36 years in 1950 to 57 years in 1957. Generally speaking, the first 8 years of the PRC are seen as being the most successful period of CCP rule under Mao's control (Schoppa, 2002).

\section{Great Leap Forward and Famine (GLF): 1958-1961}

The Great Leap Forward was an ambitious attempt by the communist government to accomplish the economic and technical development of China at a faster pace and with greater results than other nations. People's communes were created in the countryside and in a few urban areas. By the fall of 1958, some 23,500 communes, averaging 5000 households each, were established. In this massive societal reorganization, the individual commune was planned as a self-supporting community (Worden et al., 1987).

Unfortunately, the Great Leap Forward turned out to be an economic failure (Schoppa, 2002). One consequence was a striking decline of grain production in three consecutive years (1959-1961), resulting in food shortages and drastic deterioration of the standard of living. The combination of government policy and natural disasters contributed to a devastating famine of 1959-1961 (Ashton, Hill, Piazza, \& Zeitz, 1984). The hastily implemented agricultural policy led to a decrease in agricultural labor productivity and a reduction of cultivated areas, which in turn reduced grain outputs. At the same time, droughts in north China and floods in south China between 1959 and 1960 further aggravated the decline in agricultural production.

Further, the government was misinformed about actual grain outputs; it increased grain exports in 1959 and 1960. Exaggerated food production reports by local officials led to excessive government procurement and export. Rural populations experienced worse grain shortages than urban populations in famine years (Ashton et al., 1984); urban populations were relatively insulated from the crisis because state-controlled stockpiles were used to supplement their food supplies. Three years of famine (1959-1961) 
led to massive fertility deficits and excess deaths, particularly in the rural areas (Peng, 1987).

\section{Recovery and Readjustment (RR): 1962-1965}

Faced with the collapse of the commune system, CCP leaders made extensive changes aimed at decentralizing economic and agricultural decision-making. They shifted administrative and economic planning from the commune system to small-scale production teams in 1962, and much emphasis was placed on locally realistic, efficient planning. Ideological fervor and mass movements no longer dictated production goals and management practices. By early 1965, China was well on its way to economic recovery (Worden et al., 1987).

Mao, however, continued to believe that the recently restored material incentives corrupted society. To deter capitalist trends, Mao launched the Socialist Education Movement during this period: It placed emphasis on restoring ideological purity, re-infusing revolutionary fervor into the party and government bureaucracies, and intensifying class struggle (Worden et al., 1987).

\section{The Cultural Revolution (CR I, CR II): 1966-1976}

The Socialist Education Movement paved the way for the Great Proletarian Cultural Revolution of 1966-1976. The particularly violent first phase of the Cultural Revolution (CR I) spanned from 1966 to 1969 (Schoppa, 2002), although sporadic armed combat between rival groups continued through 1971 (Blayo, 1992). Mao believed that the CCP itself was becoming too bureaucratic and conservative. He used the Red Guards, composed of middle-school and university students, to shatter the party organization, to rekindle revolutionary enthusiasm, and to destroy so-called counter-revolutionary values (Worden et al., 1987). Established cadres and professionals were removed from their positions and replaced with new ones (workers, peasants, and soldiers) who lacked education, professional training, and experience to manage the specific tasks at hand (Lin \& Xie, 1988). The result was massive civil disorder, punctuated by armed combat among rival Red Guard gangs and between gangs and other social groups (Worden et al., 1987).

A new "sent down" movement also went into effect, in which intellectuals and scholars were drafted for manual labor in order to re-educate them, and purge from them any "bourgeois" influences. The education system was disrupted in the countryside, and completely shut down in most 
cities. No new students were admitted to universities from 1966 to 1969. Large numbers of urban youth were sent away for "re-education." Over 20 million university, high school, and middle-school students were sent to the countryside and border regions (Lin \& Xie, 1988). Meanwhile, a countering rural-urban migration by an estimated 16 million people fulfilled the need for military support and factory workers in cities. The results were dramatic crossovers in social stratification and mobility, with little correlation between education and occupational attainment during 19661976 (e.g., Lin \& Xie, 1988).

From 1971 to 1977, there was a shift in emphasis (CR II). During 19711973, a third family planning program was introduced after the breakdown of the first two family planning campaigns (in 1958 and 1966). Unlike previous campaigns, the stated goal of this third campaign was very clearly to promote three norms known as "later, longer, and fewer": Later marriage, longer birth intervals, and fewer children (Peng, 1991). In practical terms, this meant the marriage age for women was recommended to be 23 in rural areas and 25 in urban areas. The corresponding ages were 25 and 27 for men. Three-five years between births were regarded as ideal (Peng, 1991).

Until 1977, the "fewer" part of the campaign aimed at three children per couple in rural areas and two children in urban areas. After 1977, rural couples were also limited to two children (Wolf, 1985). Moreover, this program also instituted a birth "quota" system. The number of births planned for each year by the central government was broken down among administrative units at different levels. Women eligible to give birth were eventually selected by their work unit or production team (Blayo, 1992;Peng, 1991, p. 38). This program later expanded and became the one child policy in 1979 (Blayo, 1992).

\section{The Post Mao Period (PMP) and the Onset of the One Child Policy (OCP): 1977}

The year 1977 marked the beginning of a new social order in China, following Mao's death in the fall of 1976. Attention was given to the so-called Four Modernizations (agriculture, industry, national defense, and science and technology). New agricultural policies, such as the self-responsibility system, allowed peasants to produce on their own initiative (Worden et al., 1987). At the same time, private industries and services started growing. The attainment of economic goals became the measure of the success or failure of policies and individual leadership (Worden et al., 1987).

In 1979, with a population of 975 million, the one-child policy was announced, although it was not carried out vigorously until 1980. It was 
intended to control long-term population growth and stimulate the viability of China's new economy. Economic incentives and disincentives were used to persuade people to comply. These varied from province to province, between rural and urban areas, and across time. The allocation of economic rewards became a burden for many poor rural communes, because communes were ultimately responsible for providing such rewards. In effect, the one-child policy proved to be locally costly; it faced high levels of opposition by individuals from all walks of life, especially in rural areas (Peng, 1991). The Chinese government has never been able to carry out the one-child policy without resistance (Wasserstrom, 1984).

Six years into the implementation of the one-child policy, major modifications occurred: various exceptions were introduced allowing people to have a second child. For example, if the first child was a girl or was disabled, a second child was allowed (Peng, 1991). The one-child policy has been carried out very strictly in urban areas, but less strictly in rural regions.

\section{MATERIALS AND METHODS}

\section{Study Areas}

I chose to work with Hebei, Shaanxi (two more rural provinces) and Shanghai (an urban municipality) because they have different ecological, demographic, and economic characteristics (Figure 1). Political events should affect people's lives differently in these three regions.

Hebei, a coastal province on the North China Plain has an area of $187,700 \mathrm{~km}^{2}$. The 1990 estimated population was around 62 million. Various crops, such as wheat, cotton, corn, rice, tobacco, peanuts, and sesame grow on the alluvial plain of eastern Hebei. The rugged Taihang Mountain Area in western Hebei, besides growing cereal crops, also produces walnuts, persimmons, dates, apricots, and a variety of fruits. Hebei has sizeable reserves of coal, iron, and petroleum. Shijiazhuang, leaning against the Taihang Range and situated in the middle south of the province, is a major city and the capital of Hebei province. It is one of the important railway hubs in China with an estimated population around 8.6 million in the mid - 1990s.

Shaanxi, an inland province on the middle reaches of the Yellow River, is located in the center of China, covering an area of $206,000 \mathrm{~km}^{2}$. Its population was estimated at approximately 33 million in 1990. It has three distinctive landforms from north to south. Northern Shaanxi belongs to the 


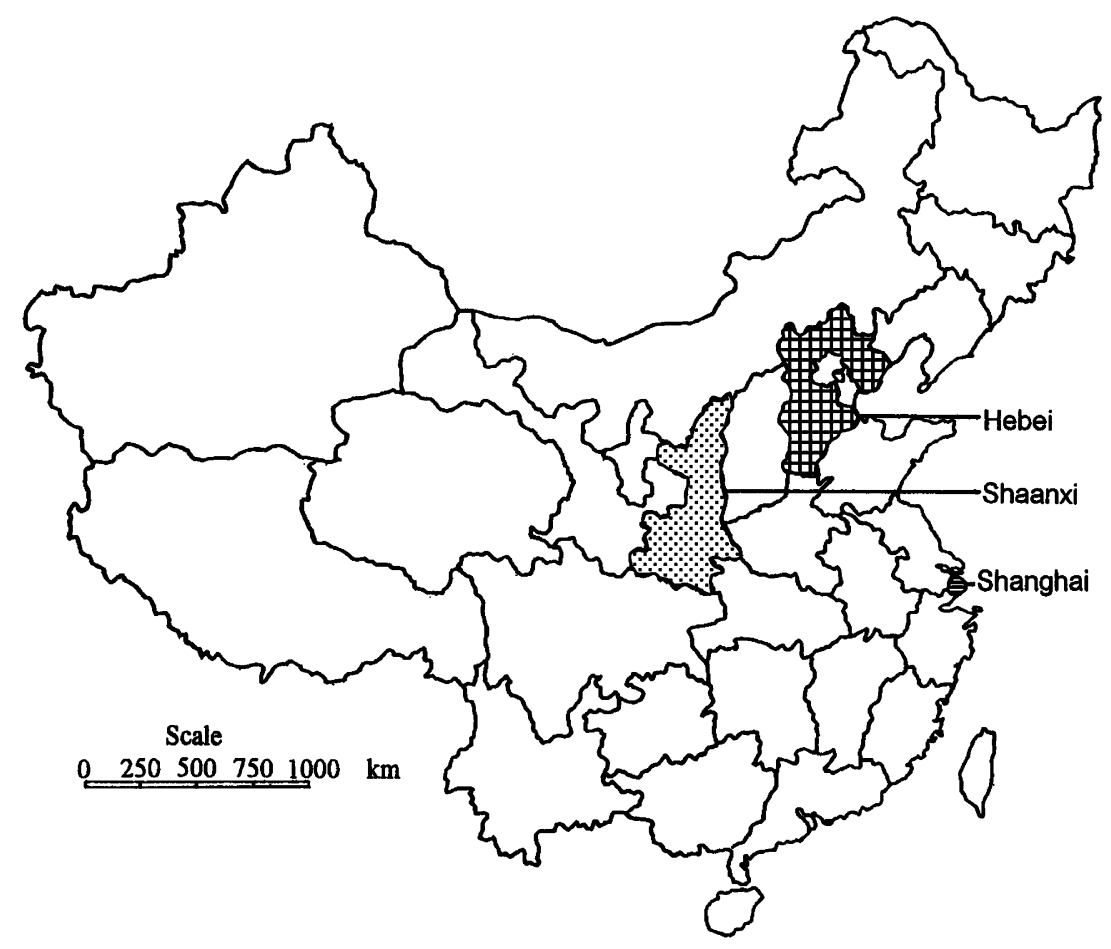

FIGURE 1. Geographic locations of Hebei, Shaanxi, and Shanghai.

Loess Plateau with an elevation of $800-1300 \mathrm{~m}$, and accounts for $45 \%$ of the province. Soil erosion in this area over the centuries has created many crisscrossing gullies. Northern Shaanxi is a farming-pastoral area producing corn, sorghum, millet and sheep. The Central Shaanxi Plain (i.e., Guanzhong Plain) has an elevation of $520 \mathrm{~m}$ on average and is famous for growing wheat and cotton. Southern Shaanxi covers the Qinling and Daba mountainous regions, with an elevation between 1000 and $3000 \mathrm{~m}$. This region accounts for $36 \%$ of the province. It is a subtropical farming area which grows rice, peas, soybeans, rape, tangerines, tea, sugar cane, lacquer, bamboo, and medicinal herbs. Shaanxi is rich in its mineral deposits, including coal, gold, and molybdenum. The province also has a large reserve of natural gas in the north. Xi'an, located in the Guanzhong Plain, is the largest city and the capital of Shaanxi. Xi'an is a main industrial and tourism center for the province. The population of $\mathrm{Xi}^{\prime}$ an was estimated around 6.6 million in the mid-1990s. 
TIH-FEN TING

Shanghai, a coastal metropolis in the southeast, covers an area of $6340 \mathrm{~km}^{2}$. Situated just south of the Yangtze Estuary, Shanghai is one of the largest ports in China and biggest cities in the world. The estimated population of Shanghai was about 13 million in 1990. Although, it is mainly urban, Shanghai still has a sizeable rural population (Dankert \& van Ginneken, 1991). The fertile Yangtze River Delta, near Shanghai, has long been important to China's agriculture.

Shanghai consistently has had the highest population density, while Shaanxi has had the lowest among the three study areas (Wang, 2000). Before the famine of 1960, Shanghai had the highest natural growth rate among the three. Since then, its natural growth rate has been the lowest. Shanghai has had the lowest fertility rate among the three since the 1960s, while Shaanxi has maintained a higher rate than Hebei most of the time. Shanghai has the highest per capita GDP. Between the early 1950s and 1970s, Hebei and Shaanxi had comparable per capita GDPs; however, Hebei has exceeded Shaanxi in its per capita GDP since the late 1970s. All these characteristics suggest that Shanghai is the most, and Shaanxi the least, developed region among the three.

Besides socio-economic variation, political upheavals had differing degrees of impacts on people in these three regions. During the Great Leap Forward famine (1959-1961), rural populations in Hebei and Shaanxi suffered more than urban population in Shanghai. On the other hand, the Cultural Revolution (especially during its early phase) was most disruptive for people's lives in Shanghai. The effectiveness of the family planning program also differs among the three areas-it has been most successful in Shanghai but least successful in Shaanxi. Although inadvertently, these political events influenced individual access to resources and the costs and benefits of family-formation decisions (such as marriage, birth) directly.

\section{Data}

I use data from the 1985 China In-depth Fertility Survey (IDFS), phase I, carried out by the Department of Population Statistics of the State Statistical Bureau (SSB) of the PRC, in cooperation with the International Statistical Institute, Voorburg, The Netherlands. The IDFS was largely inspired by the example of the World Fertility Survey carried out between 1973 and 1985. Details of survey methodology and main findings were published in the Principle Report (SSB, 1986a).

The IDFS, phase I, covered Hebei, Shaanxi, and Shanghai. For each region, the IDFS used a stratified, multistage sampling design to cover the whole area, in the hope that information collected from the survey would be 
representative. The IDFS questionnaire consisted of three parts: a community questionnaire, a household questionnaire to determine eligible respondents (women ever married and aged 15-49 years), and an individual questionnaire to interview each eligible woman. The individual questionnaire included eight major sections, including interview characteristics, respondent's and relatives' background, respondent's marital history, respondent's fertility history, knowledge and use of contraception, respondent's fertility preferences, fertility summary, birth history, and pregnancy history. A total of 13,307 married women of childbearing age were interviewed: 5080 from Hebei, 4084 from Shaanxi, and 4143 from Shanghai (SSB, 1986b; see also Dankert \& van Ginneken, 1991).

Although the survey covered women aged 15-49 years, I excluded women below age 20 because they comprised very small portions of respondents from Hebei $(0.7 \%)$ and Shaanxi $(1.2 \%)$; and no respondent from Shanghai was younger than 20 (see Dankert \& van Ginneken, 1991, Table 2). I divided women in my sample into six age groups (20-24, 25-29, 30-34, 35-39, 40-44, and 45-49) for age-specific fertility analysis.

\section{RESULTS}

Government Decisions Can Affect Reproductive Benefits and Costs

Birth and death rates fluctuated in response to government policies for the three study areas (and for China as a whole) between 1949 and 1999 (Figure 2). There were both within-area and between-area variations through time.

During the Transition period (TTS: 1949-1957), falling birth rates across Hebei, Shaanxi, and Shanghai coincided with the beginning of the first family-planning program in 1956. However, birth rates rose again when

FIGURE 2. Birth rates and death rates for Hebei, Shaanxi, Shanghai, and China as a whole, 1949-1999. TTS: transition to socialism, 1949-1957; GLF: great leap forward, 1958-1961; R\&R: recovery and readjustment, 1962-1965; CR I: first half of the cultural revolution, 1966-1971; CR II: second half of the cultural revolution, 1972-1976, overlapping with the launch of the later-longer-fewer family-planning campaign; PMP: post mao period, 1977-1979; OCP: one child policy era, 1980. (Source: Comprehensive Statistical Data and Materials on 50 years of New China, China Statistics Press, 1999.) 
TIH-FEN TING

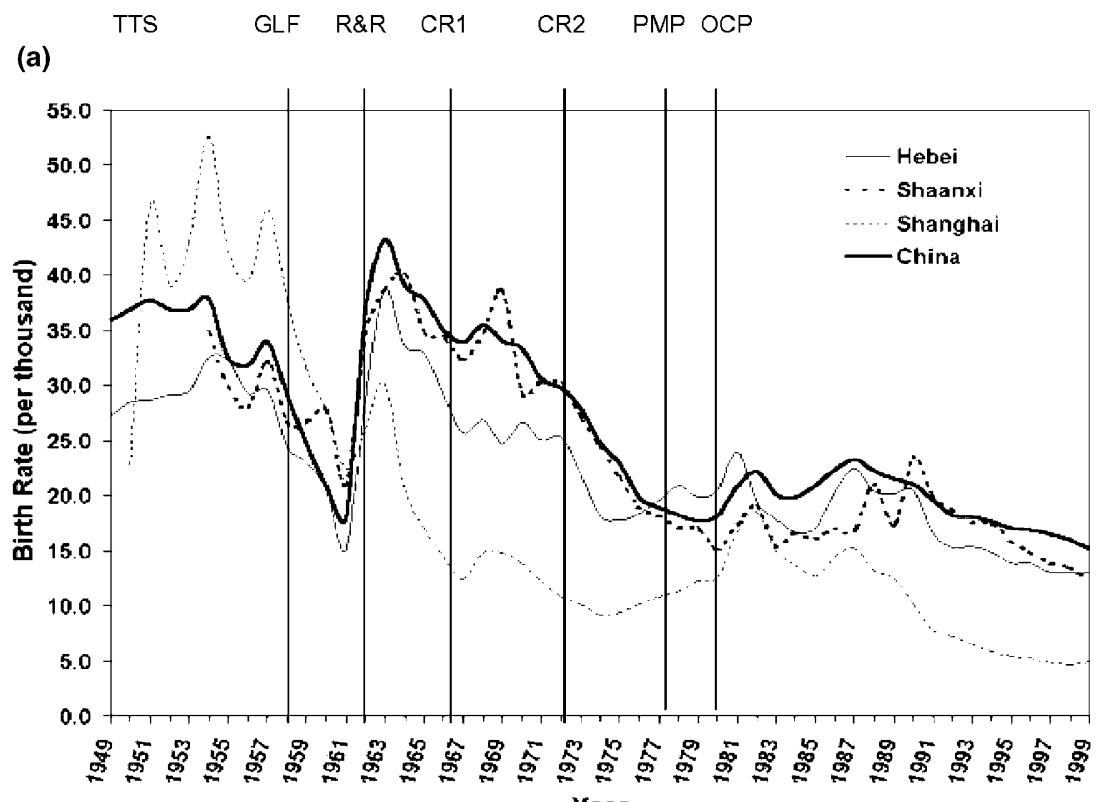

(b)

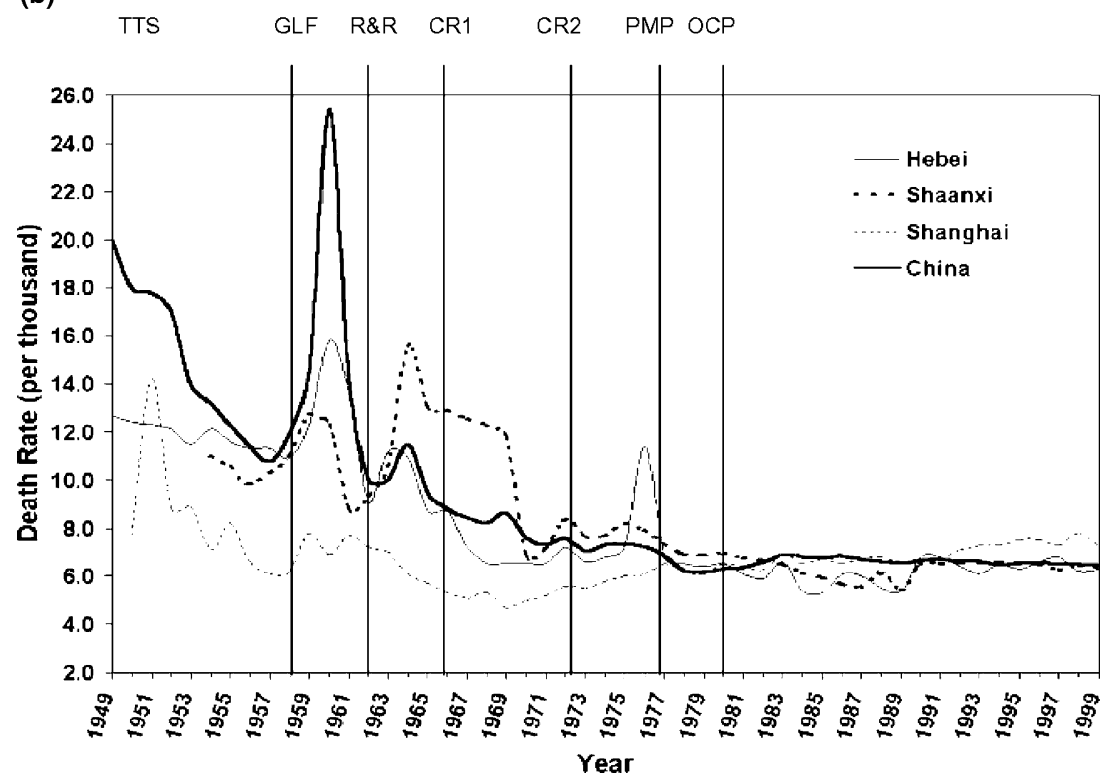


the political winds turned against birth control, during the Anti-rightist campaign of 1957. Meanwhile, death rates declined in a relatively steady fashion. In general, people in Shanghai were much better off than those from the rural provinces of Hebei and Shaanxi in terms of mortality.

During the Great Leap Forward and the subsequent famine (GLF: 1958-1961), birth rates dropped sharply in all study areas, reaching their lowest point in 1961. Between 1958 and 1961, government birth-control apparatuses ceased to function as well. Death rates climbed up precipitously, especially among the largely rural populations of Hebei and Shaanxi. Hebei and Shaanxi suffered more deaths than urbanized Shanghai because of greater grain shortages in rural China.

As soon as the Leap and famine ended, fertility increased, reaching a peak in 1963-1964. Birth rates remained relatively high during the Recovery period (R\&R: 1962-1965), although the trend was slightly negative. A second family-planning campaign was launched at the end of 1962 in response to the tremendous fertility surge after the famine. This campaign was more successful among urban populations than rural ones, which in part accounted for a much greater reduction in fertility for Shanghai than Hebei and Shaanxi after 1963. In fact, family planning established a strong footing in Shanghai during that time.

Death rates fell immediately after periods of massive famine deaths. This was particularly true for Hebei and Shaanxi where famine was more serious compared to Shanghai. However, it is not clear why Shaanxi suffered an extremely high mortality level in 1964 (even higher than the national average) when China was recovering from the Great Leap Forward crisis.

The second family-planning campaign was disrupted by the inception of the Cultural Revolution in 1966. As a result, there were upswings in birth rates for Hebei, Shaanxi, and Shanghai during the early phase of the Cultural Revolution (CR I: 1966-1971). Alarmed by the soaring growth in population, the Chinese government began to promote its third family-planning campaign in 1971. Consequently, birth rates fell during the second half of the Cultural Revolution (CR II: 1972-1976). Shaanxi had a much higher mortality rate in the beginning of the Cultural Revolution than did Hebei and Shanghai. In 1976, the final year of the Cultural Revolution, a devastating earthquake leveled the city of Tangshan in Hebei, creating a sudden upsurge in mortality level for Hebei (Figure 2). After the Cultural Revolution, death rates remained relatively low and stable; they did not fluctuate in the way birth rates did after the Cultural Revolution. 
After Mao's death in 1976, China's political focus shifted to economic development instead of political struggle. The Chinese government deemed population growth a serious threat to national economic development. In 1978, family planning became, for the first time, an article of the Chinese Constitution (Peng, 1991). By now, the third family-planning program had been very successful, lowering the natural increase rate by half compared to when the program first started in 1971. Nevertheless, as large cohorts born in the pre- and post-leap eras approached the age of marriage and childbearing, the Chinese government was convinced that strong measures were needed in order to speed up the process of modernization. Consequently, the "one child per family" policy was put forward in 1979.

In the early 1980s, an increase in fertility rates took place across all three study areas, despite the new one-child policy. This rise resulted from a new marriage law in January 1981, which replaced the old regulations implemented in 1950. The new law raised the legal minimum age for marriage to 20 (from 18) for women, and 22 (from 20) for men (Blayo, 1992; Peng, 1991). However, since at least the early 1970s during the third family-planning program, the legal minimum age stipulated by the 1950 marriage law had been ignored, largely replaced by the local authority-recommended age of 23 for rural women and 25 for their urban counterparts. Therefore, in practice, the new law of 1981 unexpectedly lowered the age at marriage and resulted in a wave of relatively early marriage and motherhood (Figure 2; also see Blayo, 1992).

The decade of the1980s was a period of fertility ups and downs as the one-child policy was being tested, modified, and reaffirmed. For example, in 1984 the government issued a modification of the strict policy known in Chinese as "open a small hole to block a big gap." In essence, this modification allowed rural couples with real difficulties, or only one daughter, to bear a second child. Local birth-planning authorities were given more freedom in stipulating rules and setting population targets according to local conditions.

However, the adjustments of the policy were not exercised without contention. It was the center of a constant dispute between hard-liners and liberals within the party (see Scharping, 2003). Since 1990, the advocates of a hard-line one-child policy have held the upper hand in shaping China's population policy. Concerned about the high number of excess births from the previous decade, they seized the opportunity to tighten birth-planning (Scharping, 2003). The steady downward trend of the birth rates in Hebei, Shaanxi, and Shanghai since 1990 coincides with the ascendancy of hard-line policies. 


\section{Age-specific Marital Fertility}

The previous section examines the impacts of government decisions on aggregate demographic patterns for each study area. However, these policies also affected individual fertility for women born in different eras (who thus faced different social/political pressures during their reproductive prime).

In all cohorts, women from both Hebei and Shaanxi (the more rural provinces) had higher age-specific marital fertility rates (ASMFRs) than Shanghai women (Figure 3). Regardless of region, women in the 45-49 years cohort had higher ASMFRs than women in any other cohorts (although ASMFRs quickly converged for Shanghai women after age 30 - with the exception of the rates at age 20-24.

Women aged 45-49 in 1985 had their prime reproductive years before the third family-planning program was in place. Thus, their fertility remained high compared to women in younger cohorts (except in famine years). Women aged 45-49 in this sample faced famine in 1960 when they were 20-24 years old, which largely explains why they had lower ASMFRs at such an age than the subsequent cohorts (Figure 3). Moreover, rural populations experienced greater severity of grain shortages than urban populations in famine years. Consequently, compared to Shanghai women, those from rural regions (Hebei and Shaanxi) did suffer a greater degree of reduction in their marital fertility at age 20-24.

Women aged 40-44 in 1985 were 20-24 years old in 1965 when China was in recovery from the failure of the Great Leap Forward and the subsequent great famine. Across regions, this group of women showed high marital fertility at age 20-24 (Figure 3).

Women 35-39 years old in 1985 experienced the early phase of the Cultural Revolution in 1970 when they were $20-24$ years old. The Cultural Revolution caused tremendous disruptions to the lives of young people, especially in urban areas. Shanghai women in this cohort had lower marital fertility at age 20-24 than women in the previous cohorts, including those who went through the great famine at the same age (Figure 3c).

Regardless of regions, women's marital fertility peaked at age 25-29 for each cohort-except women who were 35-39 in 1985 (Figure 3). Women in this particular cohort were 20-24 years old in 1970, and 25-29 years old in 1975 . The relatively stable and low marital fertility rates at these two times (especially for women from Hebei and Shanghai) were possibly the results of delayed marriage, delayed parenthood, and reduced family size in response to the Cultural Revolution and the third family-planning program. 

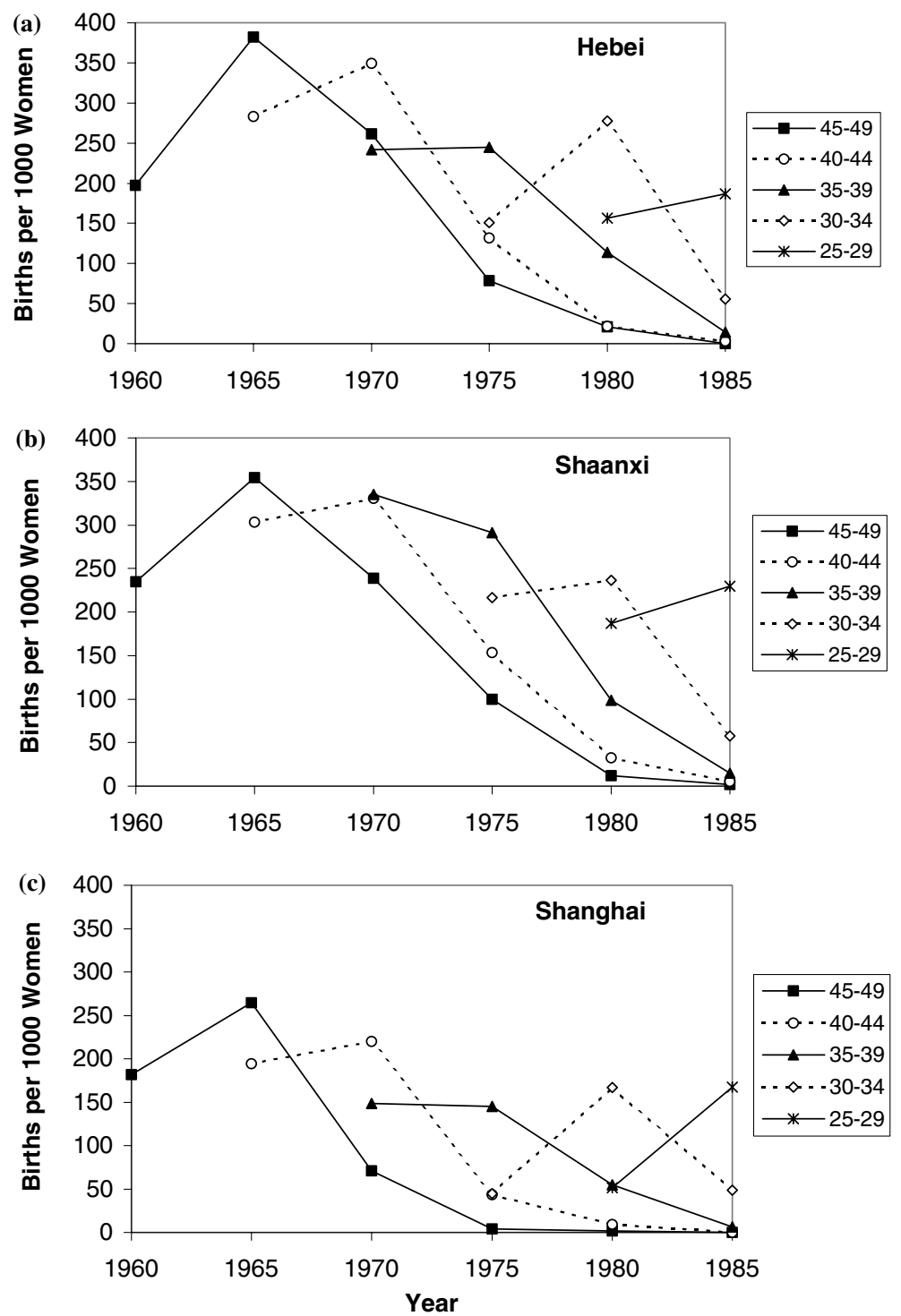

FIGURE 3. Age-specific marital fertility rate by cohorts and provinces. (a) Hebei Province, (b) Shaanxi Province and (c) Shanghai. 
Women in the 30-34 and 25-29 years cohorts were 20-24 years old in 1975 and 1980, respectively. Across regions, women in both cohorts had the lowest, and almost identical, marital fertility rates at age 20-24 (Figure 3). The low ASMFRs for women in these two young cohorts were the results of the third family-planning program, first launched in early 1970s, and the subsequent one-child policy in 1979.

\section{DISCUSSION}

During the second half of the 20th century, not only the history of China, but people's reproductive lives and resulting demographic patterns, have been affected by a series of social and political upheavals. Government policies, along with regional variations in geographic, social, and economic conditions, strongly influenced individual access to resources in China. Variations in timing and intensity of women's reproductive patterns reflect these differentials in their access to resources, and the kinds of tradeoffs they made subsequently.

Analyses of Chinese fertility patterns reveal tremendous regional variation. Fertility varies across all levels of regional and local divides. That is, fertility differs at the provincial level (Peng, 1991; Poston, 1988), county level (Poston \& Jia, 1990), and all the way down to the production brigades (Freedman, Xiao, Li, \& Lavely ,1988). Moreover, the range of fertility variation within China is as broad as that for the entire world during the same period. For example, in 1981, the lowest total fertility rate in China (e.g., 1.3 in Shanghai) was comparable to that for some of the most developed countries like Denmark. Meanwhile, the highest rate in 1981 (4.4 for the interior Guizhou province) was similar to rates of other populous developing countries such as Indonesia (Peng, 1991; Poston, 1988).

Other things being equal, delayed marriage inevitably leads to older ages at first and subsequent births. In China, where marriage is universal for women and childbearing outside marriage is very rare, age at marriage thus is closely linked to fertility patterns (see also Peng, 1991). In this study, Shanghai women married the latest; in other areas, urban women also married later than their rural counterparts (see Ting, 2003).

Differentials in socioeconomic development, and the prominence and effectiveness of the family-planning program (which promotes late marriage among other things), account at least in part for differences in ages at marriage among women from Hebei, Shaanxi, and Shanghai in this study (Ting, 2003). High degrees of economic development and family-planning effort have been associated with delayed marriage in China (Peng, 1991) as 
elsewhere. Shanghai is the most, and Shaanxi the least, "developed" among the three study sites (above). The family-planning program has gained a strong footing in Shanghai since the 1960s. In general, family-planning also was carried out earlier and more efficiently in Hebei than Shaanxi (Peng, 1991). In China as elsewhere, urban areas tend to be more economically developed than rural areas, and family planning has typically been more successful in urban than rural areas (Peng, 1991).

During the Great Leap Forward, droughts caused the loss of $54 \%$ of the crop in Shaanxi in 1959, and $60 \%$ in Hebei in 1960 (Ashton et al., 1984). Age-specific fertility rates fell for women in Shaanxi and Hebei as a result of drought and famine. Similar situations have also been reported elsewhere for a number of historical populations (e.g., Low, 1989; Low \& Clarke, 1993; Wrigley \& Schofield, 1981).

Changes in women's age-specific fertility rates were not as dramatic in Shanghai as in Hebei and Shaanxi, because the urban population was insulated from the agrarian crisis through grain rationing systems and supplements from state-controlled stockpiles (Ashton et al., 1984). Rather, institutions such as the family-planning program have had larger effects on age-specific fertility rates for women in Shanghai compared to women in Hebei and Shaanxi. In Shanghai, age-specific fertility rates for women of different age cohorts have converged quickly since 1970 — a sign of the effectiveness of the family-planning program.

China's commitment to birth-planning and population control is without precedent in world history. Family-planning was first written into the constitution in 1978. In 1982, it became an indispensable part of national policy. Moreover, the law on population and family-planning, the first of its kind, was promulgated in December 2001; it went into effect in September 2002. The law now provides a legal footing for the work on family-planning nation-wide, and aims to stabilize China's population at 1.5 billion by 2020 .

\section{CONCLUSION}

China's political turmoil during the 20th century provides a rich focus for analysis. The population history of China during the second half of the last century reflects strong state interventions in the lives of its citizens. Some Chinese policies were directed at affecting population growth through regulating marriage and fertility - but this analysis makes it clear that in many cases, policies not intended to influence fertility nonetheless affected individuals, in their access to resources, their ability to marry, and their 
ability to raise well-nourished children. Of the fluctuations in age-specific fertility, and birth and death rate analyzed here, few are responses to forces we commonly consider "environment" (e.g., the earthquake in Hebei); more frequent and dramatic are the responses to political decisions not even aimed at fertility and mortality. Political decisions are thus, in fact, an "environmental" force that must be analyzed in many cases.

\section{REFERENCES}

Ashton, B., Hill, K., Piazza, A., \& Zeitz, R. (1984). Famine in China, 1958-1961. Population and Development Review 10, 613-645.

Blayo, Y. (1992). Political events and fertility in China since 1950. Population: An English Selection 4, 209-232.

Bonggarts, J., \& Potter, R. G. (1983). Fertility, Biology, and Behavior: An Analysis of the Proximate Determinants. Academic Press.

Clarke, Alice L., \& Low, B. S. (2001). Testing evolutionary hypotheses with demographic data. Population and Development Review 27(4), 633-660.

Daan, S., \& Tinbergen, J. M. (1997). Adaptation of life histories. In J. R. Krebs, \& N. B. Davies (Eds.), Behavioural Ecology: An Evolutionary Approach (pp. 311-333). London: Blackwell.

Dankert, G., \& van Ginneken, J. (1991). Birth weight and other determinants of infant and child mortality in three provinces of China. Journal of Biosocial Science 23, 477-489.

Freedman, R., Xiao, Z., Li, B., \& Lavely, W. (1988). Local area variations in reproductive behaviour in the People's Republic of China, 1973-1982. Population Studies 42, 39-57.

Hill, K., \& Hurtado, A. M. (1996). Ache Life History: The Ecology and Demography of a Foraging People. New York: Aldine de Gruyter.

Johnson, K. A. (1983). Women, the Family and Peasant Revolution in China. Chicago, IL: University of Chicago Press.

Kaplan, H. (1994). Evolutionary and wealth flows theories of fertility: Empirical tests and new models. Population and Development Review 20, 753-791.

Lessells, C. M. (1991). The evolution of life history. In J. R. Krebs, \& N. B. Davis (Eds.), Behavioural Ecology: An Evolutionary Approach (pp. 32-68). London: Blackwell.

Lin, N., \& Xie, W. (1988). Occupational prestige in urban China. American Journal of Sociology 93, 793-832.

Low, B. S. (1989). Occupational status and reproductive behavior in nineteenth-century Sweden: Locknevi Parish. Social Biology 36, 82-101.

Low, B. S. (1998). The evolution of human life histories. In C. Crawford, \& D. L. Krebs (Eds.), Handbook of Evolutionary Psychology (pp. 131-161). Mahwah, NJ: Lawrence Earlbaum Assoc.

Low, B. S. (2000). Why Sex Matters: A Darwinian Look at Human Behavior. NJ: Princeton University Press.

Low, B. S., \& Clarke, A. L. (1993). Resource control, fertility, and migration. In G. Ness, W. Drake, \& S. Brechin (Eds.), Population-Environment Dynamics: Ideas and Observations (pp. 195-224). Ann Arbor, Ml: University of Michigan Press.

Low, B. S., Clarke, A. L., \& Lockridge, K. A. (1992). Toward an ecological demography. Population and Development Review 18, 1-31.

Meisner, M. (1999). Mao's China and After: A History of the People's Republic. 3rd ed. New York: The Free Press.

Parish, W. (1984). Destratification in China. In J. Watson (Ed.), Class and Social Stratification in Post-Revolution China (pp. 84-120). MA: Cambridge University Press. 
TIH-FEN TING

Peng, X. (1987). Demographic consequences of the Great Leap Forward in China's provinces. Population and Development Review 13, 639-670.

Peng, X. (1991). Demographic Transition in China: Fertility Trends Since the 1950s. Oxford: Clarendon Press.

Poston, D. L. (1988). Fertility and family planning in China: An analysis of provincial patterns. Journal of Biosocial Science 20,379-391.

Poston, D. L., \& Jia, Z. (1990). Socioeconomic structure and fertility in China: A county level investigation. Journal of Biosocial Science 22, 507-515.

Roff, D. A. (1992). The Evolution of Life Histories: Theory and Analysis. New York: Chapman and Hall.

Roff, D. A. (2002). Life History Evolution. Sunderland, MA: Sinauer Associates.

Scharping, T. (2003). Birth Control in China 1949-2000. London: Routeledge Curzon.

Schoppa, R. K. (2002). Revolution and Its Past: Identities and Change in Modern Chinese History. NJ: Prentice Hall.

State Statistical Bureau (1986a). China In-Depth Fertility Survey. Principal Report, Vols 1 \& 2. Beijing: Department of Population Statistics of the State Statistical Bureau.

State Statistical Bureau (1986b). China In-Depth Fertility Survey. Preliminary Report. Beijing: Department of Population Statistics of the State Statistical Bureau.

Stearns, S. C. (1992). The Evolution of Life History. UK: Oxford University Press.

Ting, T. -F. (2003). Human reproductive ecology in revolutionary China. PhD Dissertation. Ann Arbor, Ml: University of Michigan.

Wang, G. (2000). The distribution of China's population and its changes. In X. Peng, \& Z. Guo (Eds.), The Changing Population of China (pp. 11-19). London: Blackwell.

Wasserstrom, J. (1984). Resistance to the one-child family. Modern China 10, 345-374.

Wolf, M. (1985). Revolution Postponed: Women in Contemporary China. CA: Stanford University Press.

Worden, R. L., Savada, A. M., \& Dolan, R. E. (1987). China: A country study. 4th ed. Washington, DC: Library of Congress.

Wrigley, E. A., \& Schofield, R. S. (1981). The Population History of England, 1541-1871: A Reconstruction. Cambridge, MA: Harvard University Press. 